\title{
Modification and Verification of Fracture Criterion of BR1500HS Based on Freudenthal Fracture Criterion
}

\author{
XIA Yu-feng ${ }^{1, a}$, YE Cai-hong ${ }^{1, b}$, Ren $\mathrm{Li}^{1, \mathrm{c}}$, Wang $\mathrm{Li}^{1, \mathrm{~d}}$ \\ College of Material Science and Engineering, Chongqing University Chongqing, China \\ a20130902005@cqu.edu.cn, b15062826101@163.com, 'Renli1991@cqu.edu.cn, dawilly@cqu.edu. \\ cn
}

Keywords: BR1500HS ultrahigh strength steel ; Finite element simulation; Fracture criterion

\begin{abstract}
The hot tensile test of BR1500HS ultrahigh strength steel was carried out on Gleeble3500 thermo-mechanical simulator. The process was predicted by finite element simulation based on Freudenthal fracture criterion. Then, the Freudenthal fracture criterion is modified based on the relationship between the Freudenthal fracture criterion and fracture threshold with deformation conditions. The modified fracture criterion was applied to the DEFORM software, and the results show that the modified Freudenthal fracture criterion has high accuracy and can be used to predict the damage and fracture of BR1500HS.
\end{abstract}

\section{I.INTRODUCTION}

With the high requirements for material in modern automobile manufacturing industry, ultrahigh strength steel sheets are widely used in automobile parts for its light weight, high strength and low $\operatorname{cost}^{[1]}$. However, the strength of ultrahigh strength steel is too high, in order to improve the forming ability, foreign scholars have proposed the hot stamping process of quenchable boron steel ${ }^{[2]}$. Although the forming ability of ultrahigh strength steel could be improved in the hot stamping process, there may be cracking, wrinkling and other defects in the forming process ${ }^{[3]}$.

In order to avoid the fracture of the sheet and the waste of material, many scholars have studied the forming limit prediction.Yu et al. used ductile fracture criterion in numerical simulation to predict the drawing and bulging forming limit for aluminum alloy sheet, the results showed ductile fracture criterion can predict the aluminum alloy sheet forming limit[4]. Zhou et al. used Oyane ductile fracture criterion to predict the forming limit for nickel coated sheet, and the prediction results were in good agreement with the experimental results[5]. Yu et al. used numerical simulation method to predict the forming limit for SPCC based on Oyane ductile fracture criterion and obtained a sheet metal forming limit diagram[6].Wu et al. improved and applied the Lemaitre ductile fracture criterion in spinning forming process, the results showed that the improved Lemaitre ductile fracture criterion has higher prediction accuracy[7]. Huang et al. proposes a set of ductile fracture criterion for a variety of deformation conditions by analyzing and comparing the five kinds of ductile fracture criterion commonly used in engineering[8]. The above researches are mainly about the establishment of fracture criterion on the cold forming, but not on the hot forming process, and not about forming limit prediction for ultrahigh strength steel sheet. The temperature and strain rate in the cold and hot forming process are completely different, so the forming limit prediction method which is applied in cold forming is not suitable for hot forming[3]. Therefore, in order to avoid fracture of the sheet in hot forming process, it is needed to establish an appropriate fracture criterion to predict the forming limit for ultrahigh strength steel[9].

In the present work, BR1500HS ultrahigh strength steel was chosen as the research object. The hot tensile test was carried out on Gleeble3500 thermo-mechanical simulator and the tensile process was simulated by DEFORM software. Based on the relationship between Freudenthal fracture criterion, the fracture damage threshold and deformation condition, the Freudenthal fracture criterion was modified by the reverse analysis method. Then the modified fracture criterion was applied to the DEFORM software. The results of finite element simulation are in good agreement with the experimental results, so the modified fracture criterion can be used to predict the damage 
and fracture of BR1500HS in actual production.

\section{Experimental Materials And Methods}

The BR1500HS hot rolled steel sheet produced by Baosteel was used in the experiment. The tensile specimens were prepared according to the standard of GB/T 4338-2006. The twodimensional figure of tensile specimen is shown in Fig.1, the original gauge length of the specimens is $25 \mathrm{~mm}$, the width is $12.5 \mathrm{~mm}$, the thickness is $1.8 \mathrm{~mm}$. In order to avoid the influence of work hardening on microstructure and tensile properties of materials, the method of wire cutting was used to process the specimens. Location holes were bored at both ends on the axis of the specimens to avoid the slide of the specimens in the hot tensile process.The edges of specimens were filleted, and the surfaces of specimens were polished with fine sandpaper to avoid stress concentration occurring in hot tensile. A thermocouple was welded at the center of sample surface and connected with the thermo-mechanical simulator to monitor and controll temperature. Hot tensile test was carried out on a Gleeble3500 thermo-mechanical simulator that can be used for rapid heating and heat preservation by using a unique electric resistance heating system. The tongs of high thermal conductivity was applied to realize rapid cooling.

The experimental procedure for the hot tension tests can be described as follows:

(1)The specimens were heated to $1223 \mathrm{~K}$ at a speed of $5 \mathrm{~K} / \mathrm{s}$ and preserved for 180 s to ensure obtaining the fully austenitic microstructure.

(2)The specimens were cooled at the speed of $15 \mathrm{~K} / \mathrm{s}$ to $1223,1123,1023,873 \mathrm{~K}$ respectively, and preserved for 10 s to eliminate the internal temperature gradient.

(3) The specimens were carried out constant temperature tensile in the different deformation temperatures $(1223,1123,1023,873 \mathrm{~K})$ at the strain rate of $0.01,0.1,1$ s- 1 respectively until snapped.

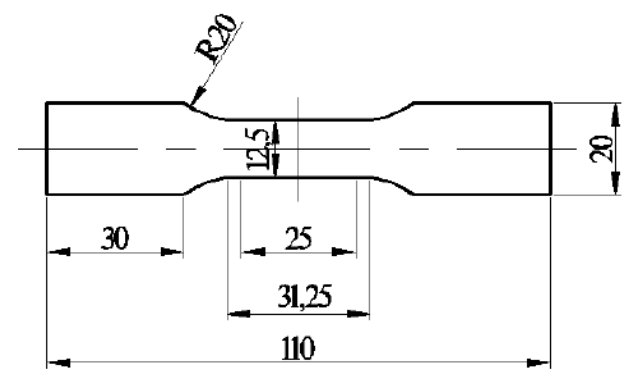

Fig.1 two-dimensional figure of tensile test specimen

\section{III.Ductile Fracture Criterion}

Freudenthal et al. argues that when the energy in unit volume of the material reaches a certain threshold, the macrocrack will occur[10]. Based on this theory, the expression was given as follows:

$$
\int_{0}^{\varepsilon_{1}}(1)=C
$$

Where $\bar{\sigma}$ is equivalent stress and $\bar{\varepsilon}$ is equivalent strain, $\varepsilon_{\mathrm{f}}$ is fracture strain of materials under different deformation conditions ${ }^{[11]}$. According to the definition of Freudenthal model, the damage threshold $\mathrm{C}$ is the integral value for the flow stress to strain in the whole deformation process. According to other scholars' studies on the fracture criterion, the hardening exponents of the material under different deformation conditions can be solved by true stress-strain curves obtained by the hot tensile test, and the point at which the hardening exponent of the material changed obviously is regarded as the fracture strain, which is shown in Fig.2. Table 1 shows that the fracture strains under the different deformation conditions of BR1500HS. According to the stress-strain curves, the $\mathrm{C}$ values at different temperatures and strain rates acquired by the integral calculation in the Origin software are shown in Table 2. 


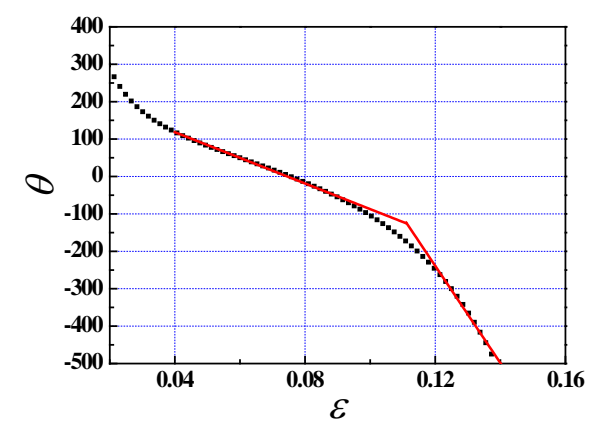

Fig.2 The determination of fracture strain with the temperature of $1123 \mathrm{~K}$ and strain rate of 0.01

TABLE 1 The fracture strain of BR1500HS steel at different deformation conditions

\begin{tabular}{|c|c|c|c|}
\hline \multirow{2}{*}{$\begin{array}{c}\text { Temperture } \\
(\mathrm{K})\end{array}$} & \multicolumn{3}{|c|}{ Strain rate(s $\left.\mathrm{s}^{-1}\right)$} \\
\cline { 2 - 4 } 873 & 0.01 & 0.1 & 1 \\
\hline 1023 & 0.137 & 0.209 & 0.225 \\
\hline 1123 & 0.111 & 0.125 & 0.157 \\
\hline 1223 & 0.117 & 0.120 & 0.155 \\
\hline
\end{tabular}

TABLE 2 The damage threshold of BR1500HS steel at different deformation conditions

\begin{tabular}{|c|c|c|c|}
\hline \multirow{2}{*}{$\begin{array}{c}\text { Tempertur } \\
\mathrm{e}(\mathrm{K})\end{array}$} & \multicolumn{3}{|c|}{ Strain rate $\left(\mathrm{s}^{-1}\right)$} \\
\cline { 2 - 4 } & 0.01 & 0.1 & 1 \\
\hline 873 & 20.7 & 40.4 & 53.127 \\
\hline 1023 & 8.25 & 16.5 & 29.6 \\
\hline 1123 & 7.05 & 10.4 & 17.8 \\
\hline 1223 & 6.38 & 9.46 & 16.3 \\
\hline
\end{tabular}

According to Table 2, the damage threshold of material changes with the change of deformation conditions. The damage threshold decreases with the increase of temperature, which is due to the atomic energy increases and inter-atomic bonding force decreases with the increase of temperature. The damage threshold increases with the increase of the strain rate, which is due to the internal dislocation density and the strength of material increase with increase of the strain rate. The relationship between the material damage threshold and material deformation conditions is shown in Fig. 3 and can be expressed as (2) based on linear regression analysis.

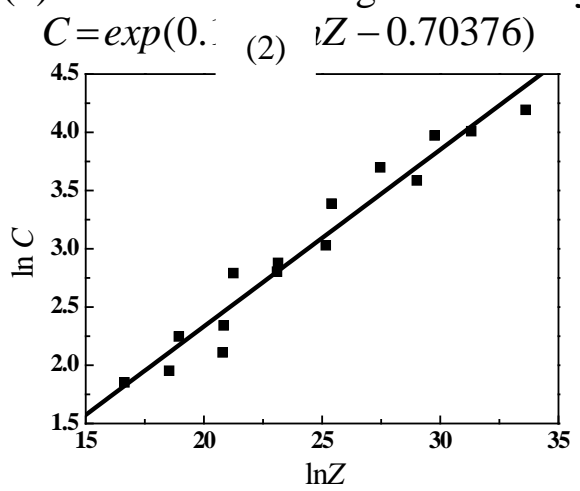

Fig.3 The relationships between $\ln C$ and $\ln Z$

Due to the $C$ values in the DEFORM software can only be set to a constant, fracture criteria need to be modified as follows combining (1) with (2):

$$
\begin{aligned}
& \int^{\varepsilon_{\mathrm{f}}} \bar{\sigma} d \bar{s} \\
& \overline{\exp (0.15} \text { (3) } \overline{1.70376)}=C^{\prime}
\end{aligned}
$$

Where the value of damage threshold $C^{\prime}$ is 1. 


\section{Modification And Verification of Fracture Criterion}

The comparison of tensile length of the specimen in the actual experiment with finite element simulation results is shown in Table 3 . When the strain rate is $0.01 \mathrm{~s}^{-1}$ and the temperature is $1233 \mathrm{~K}$, the simulation results and the experimental results are only about $0.7 \mathrm{~mm}$, but the accuracy of the simulation begin to deviate with the increase of strain rate. The elongation of the material decreases with the increase of strain rate, which is not consistent with the experiment.

TABLE 3 The comparisons of experimental elongation with model ones

\begin{tabular}{|c|c|c|c|c|c|c|}
\hline \multirow{2}{*}{$\begin{array}{c}\text { Tempertur } \\
\text { e(K) }\end{array}$} & \multicolumn{6}{|c|}{ Strain rate(s $\left.\mathrm{s}^{-1}\right)$} \\
\cline { 2 - 7 } & $\begin{array}{c}\text { exper } \\
\text { iment }\end{array}$ & $\begin{array}{c}\text { simul } \\
\text { ation }\end{array}$ & $\begin{array}{c}\text { exper } \\
\text { iment }\end{array}$ & $\begin{array}{c}\text { simul } \\
\text { ation }\end{array}$ & $\begin{array}{c}\text { exper } \\
\text { iment }\end{array}$ & $\begin{array}{c}\text { simul } \\
\text { ation }\end{array}$ \\
\hline 873 & 6.05 & 5.046 & 8.55 & 4.578 & 10.25 & 5.279 \\
\hline 1023 & 4.95 & 5.475 & 7.3 & 3.922 & 9.425 & 3.413 \\
\hline 1123 & 4.725 & 4.11 & 7.075 & 3.347 & 9.3 & 2.896 \\
\hline 1223 & 7 & 3.713 & 6.4 & 2.758 & 7.925 & 2.664 \\
\hline
\end{tabular}

In order to improve the accuracy of the finite element analysis, the inverse analysis method was used to determine the damage threshold of the BR1500HS under different deformation conditions by means of the actual elongation of the material. Firstly, the material damage threshold was set to a large value, and the hot tensile under different deformation conditions were simulated. Secondly, when the elongation of the material in the simulation was consistent with the elongation of the test, the maximum damage value of the material was recorded. The value was used as the damage threshold of material under relevant deformation. The fracture damage threshold in different deformation conditions is shown in Table 4.

TABLE 4 The revised damage threshold of BR1500HS steel at different deformation conditions

\begin{tabular}{|c|c|c|c|}
\hline Temperture( & \multicolumn{3}{|c|}{ Strain rate $\left(\mathrm{s}^{-1}\right)$} \\
\cline { 2 - 4 } $\mathrm{K})$ & 0.01 & 0.1 & 1 \\
\hline 873 & 43.5 & 75 & 129 \\
\hline 1023 & 18 & 35 & 83 \\
\hline 1123 & 16 & 28 & 57 \\
\hline 1223 & 6.38 & 22 & 40 \\
\hline
\end{tabular}

According to the table 4, the damage threshold was chosen as the dependent variable, and the deformation temperature and strain rate were chosen as the independent variables based on the regression analysis by using Origin software. The three time polynomial model is shown in (4).

$$
\begin{aligned}
& \mathrm{z}=\mathrm{z}_{0}+\mathrm{a} x+\mathrm{b} y+\mathrm{c} x^{2}+\mathrm{d} y^{2}+\mathrm{f} x y+\mathrm{g} x^{2} y \\
& +\mathrm{h} x y^{2}+\mathrm{i} x^{3}+\mathrm{j}
\end{aligned}
$$

Where $\mathrm{ZO}$ is a constant, a, b, c, d, f, g, h, i, j are different coefficients respectively, $\mathrm{x}$ is the temperature variable and $y$ is the derivative of the strain rate. The value of each factor can be solved by the regression analysis, therefore:

$$
\begin{aligned}
& C^{\prime}=2317.22-5.59 x+191.60 y+0.00474 x^{2} \\
& -14.39 y^{2}-0.21 x y+0.000034 x^{2} y-0.0294 x y^{2} \\
& -0.000001385 x^{3}-18.22404 y^{3}
\end{aligned}
$$


TABLE 5 The comparisons of experimental damage with model ones

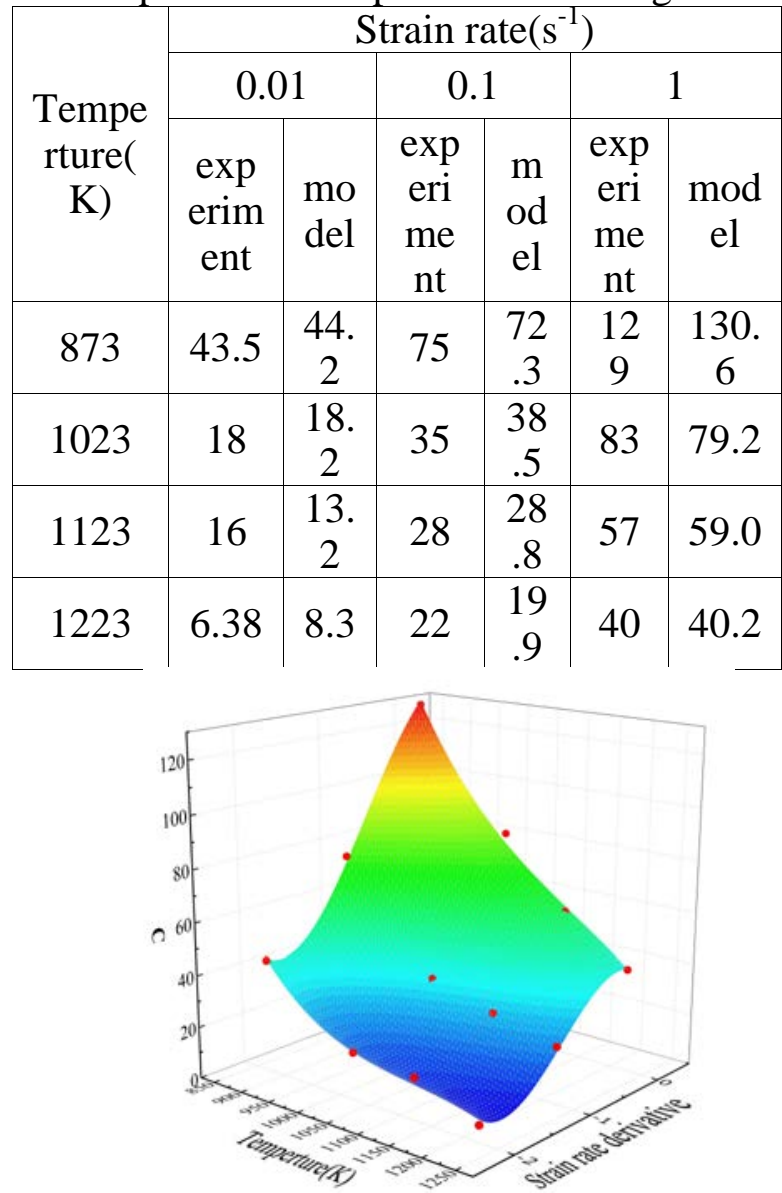

Fig.4 The damage threshold of BR1500HS steel at different deformation conditions

As is shown in Table 5, the comparison between the damage threshold obtained by the test and the damage threshold of the mathematical model under different deformation conditions. As is shown in (4), the change of the damage threshold with the deformation conditions is described in the three-dimensional graph. According to table 5 and (4), the model has a high prediction accuracy, and can be used to predict the fracture damage threshold at different deformation conditions. Therefore, the mathematical model shown as (5) can be used to describe the change of the fracture damage threshold with the deformation conditions. So the modified fracture criterion can be written in the form of (6), where the value of fracture damage threshold $\mathrm{C}$ is 1.

$$
\begin{aligned}
& C=\left(2317.22-5.59 x+191.60 y+0.00474 x^{2}-14.39 y^{2}\right. \\
& -0.21 x y+0.000034 x^{2} y-0.0294 x y^{2}-0.0000013851 x^{3} \\
& \left.-18.22404 y^{3}\right)^{-1} \int_{0}^{\varepsilon_{\mathrm{f}}} \bar{\sigma} d \bar{\varepsilon}
\end{aligned}
$$

The total length of the specimen decreas $\epsilon_{,} \ldots \ldots \ldots$.... increase of deformation temperature, and the heating position of the specimens has a large degree of shrinkage. The specimens has a large strain rate at the part of the fracture, and the strain rate at other parts of is close to 0. Above these are highly consistent with the actual test results.As is shown in (5), at the strain rate of $0.1 \mathrm{~s}-1$ and the temperature of $1123 \mathrm{~K}$, the tensile length is $7.025 \mathrm{~mm}$ when the fracture of specimen occurs. The comparison of the tensile length of the specimen in actual hot tensile with the finite element simulation based on modified fracture criterion is shown in Table 6. According to Table 6, the difference between the simulation results and the experimental results are less than $0.673 \mathrm{~mm}$, and the length of the simulation is very close to the actual test. In summary, the modified fracture criterion has high accuracy, which can be used to predict the damage and fracture of BR1500HS during hot forming process. 
TABLE 6 The comparisons of experimental elongation with model ones

\begin{tabular}{|c|c|c|c|c|c|c|}
\hline \multirow{3}{*}{$\begin{array}{c}\text { Tempe } \\
\text { rture(K } \\
)\end{array}$} & \multicolumn{6}{|c|}{ Strain rate $\left(\mathrm{s}^{-1}\right)$} \\
\hline & \multicolumn{2}{|c|}{0.01} & \multicolumn{2}{|c|}{0.1} & \multicolumn{2}{|c|}{1} \\
\hline & $\begin{array}{c}\text { experi } \\
\text { ment }\end{array}$ & $\begin{array}{c}\text { simul } \\
\text { ation }\end{array}$ & $\begin{array}{c}\text { experi } \\
\text { ment }\end{array}$ & $\begin{array}{c}\text { simul } \\
\text { ation }\end{array}$ & $\begin{array}{c}\text { experi } \\
\text { ment }\end{array}$ & $\begin{array}{c}\text { simul } \\
\text { ation }\end{array}$ \\
\hline 873 & 6.05 & 5.565 & 8.55 & 7.877 & 10.25 & 9.732 \\
\hline 1023 & 4.95 & 5.091 & 7.3 & 6.878 & 9.425 & 8.97 \\
\hline 1123 & 4.725 & 4.217 & 7.075 & 6.88 & 9.3 & 8.914 \\
\hline 1223 & 7 & 6.821 & 6.4 & 5.917 & 7.925 & 7.832 \\
\hline
\end{tabular}

Fig.5 The tensile test specimen at the strain rate of $0.1 \mathrm{~s}^{-1}$ and the temperature of $1123 \mathrm{~K}$

\section{Conclusion}

The fracture strain and damage threshold of BR1500HS ultrahigh strength steel at strain rate of $0.01 \sim 1 \mathrm{~s}-1$ and deformation temperature of 1023 1173K were obtained by calculation;

The hot tensile process was simulated by using DEFORM software and then the predictive accuracy of the fracture criterion was judged according to the comparison of simulation results with experimental results;

Freudenthal fracture criterion was modified by the reverse analysis method. The simulation results in DEFORM software by applying the modified fracture criterion are highly consistent with the test results. It indicates that the modified fracture criterion can be used to predict the damage and fracture of BR1500HS during hot forming process.

\section{REFERENCES}

[1] Zhang Lei, Zhao Yuzhang, Wang Wurong. Experimental study of hot stamping process of B1500HS ultra high born steel[J]. Journal of Shanghai Jiao Tong University, 2015, 49(1): 12-18.

[2] LI Hui-ping, ZHAO Guo-qun, ZHANG lei, et al. The development status of hot stamping and quenching of ultra high-strength steel[J]. Journal of Shandong University, 2010, 40(3): 69-74.

[3] Gu Tian. Research on ductile fracture criterion of hot stamping[D]. Harbin: Harbin Institute of Technology, 2012: 1-12.

[4] Yu Zhongqi. Forming limit prediction for aluminum alloy sheet based on the ductile fracture criterion[J]. The Chinese Journal of Nonferrous Metals, 2003, 13(5): 1223-1226.

[5] Zhou Liqun. Forming limit prediction for nickel coated sheet based on ductile fracture criterion by finite element method[J]. Materials for Mechanical Engineering, 2015, 39(2): 103-106.

[6] Yu Xinhong. Prediction of the forming limit of sheet metals based on oyane ductile fracture criterion[J]. Materials Science \& Technology, 2009, 17(5): 738-740.

[7] Wu Juan, Zhan Mei, Jiang Huabing, et al. An improved Lemaitre ductile fracture criterion and its application in the spinning forming[J]. Acta Aeronautica Et Astronautica Sinica, 2010, 32(7): 1309-1317.

[8] Huang Jiangke, Dong Xianghuai. Numerical simulation and experimental verification of ductile fracture criteria of metals[J]. Materials Science \& Technology, 2010, 18(4): 450-454.

[9] Xie Yanming, Yu Huping, Chen Jun, et al. Recent research advance of application of ductile 
fracture criteria in sheet metal forming process[J]. Journal of Harbin Institute of Technology, 2009, 41(1): 169-173.

[10] $\mathrm{Pu}$ Sihong, Wentong, Wu Wei, et al. Theoretical and experimental research on choosing criterion and critical value of ductile fracture[J]. Casting. Forging. Welding. 2009, 38(3): 18-21.

[11]Zhai Nizhi. Applications of numerical simulation to the analysis of the forming limit of sheet metals[D]. Xian: Northwestern Polytechnieal University, 2007: 12-15. 